\title{
Global climate change, geo-engineering and human health
}

Rio+20's proposed Sustainable Development Goals have the potential to redefine the course of international action on climate change. They recognise that environmental health is inextricably linked with human health, and that environmental sustainability is of paramount importance in safeguarding global health. Competition entrants were asked to discuss ways of making global health a central component of international sustainable development initiatives and environmental policy, using one or two concrete examples

io+20's Sustainable Development Goals represent a salutary advance in global discourse on climate change action. The goals acknowledge the indissoluble connection between human health and environmental sustainability. ${ }^{1}$ Climate change scenarios portend a host of health ills: the spread of tropical pathogens; inclement weather events with their attendant toll on human populations; and the degradation of terrestrial and oceanic ecosystem services resulting in increased water scarcity, food shortages, civil strife and possibly war. ${ }^{2,3}$ In short, it is clear that climate change represents profound health challenges.

Conversely, climate change mitigation represents health opportunities. Concrete examples abound on the health co-benefits of progressive climate change mitigation. ${ }^{4} \mathrm{~A}$ reduction on fossil fuel reliance from motorised transport, for instance, offers improved cardiovascular performance in an increasingly sedentary global population beset with metabolic disease. Similarly, less indoor biofuel combustion and improved air quality could ameliorate the incidence and severity of chronic obstructive pulmonary disease $^{5}$ and lung cancer, ${ }^{6}$ as well as other lung disease.

One underinvestigated dimension to climate change discourse, however, is the link between human health and geo-engineering. Geo-engineering projects are increasingly proposed as a safety valve in the event of runaway climate change and continued global disagreement over deep emissions cuts. ${ }^{7}$ Geo-engineering represents a broad church of technologies that involve manipulation of climate settings on a planetary scale to manipulate anticipated and observed climate change phenomena. The technologies fall into one of two main categories - those aimed at removing carbon dioxide from the atmosphere, and those aimed at reducing radiative forcing by deflecting sunlight. ${ }^{8}$ While the term can refer to

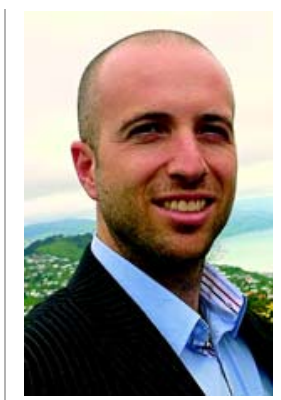

Costa S Boyages

BArts(Hons), LLB, Final Year Medical Student

School of Medicine, University of Sydney, Orange, NSW.

cboy6094@ uni.sydney.edu.au

doi: 10.5694/mjal3.10572

Online first 13/09/13 a suite of climate-modifying technologies, I've focused here on two geo-engineering technologies: fertilising oceans with iron filings to stimulate phytoplankton blooms to resorb more carbon dioxide from the atmosphere; and seeding the upper atmosphere with reflective aluminium nanoparticles or sulfur aerosols to reduce solar radiation.

While these technologies may smack of science fiction, we are clearly living in the Anthropocene age, with the problems of climate change, ozone depletion and mass extinction of species all evidence that human industrial civilisation is a geological force capable of overwhelming planetary regulation. ${ }^{9}$ Moreover, as climate change negotiations reach an impasse, geotechnology is increasingly gaining political traction, with politicians loath to navigate the diabolical policy dilemmas of deep and economically painful emissions reductions. Geoengineering poses myriad moral, ecological, security and governance challenges. However, the human health implications are a little-explored dimension to these technologies. This is vitally worth considering given the scale and irreversibility of any such possible experiment with global human health.

Technologies aiming to reduce solar radiation, for instance, pose potential health hazards. Current modalities for deflecting sunlight include sulfur and nanometallic aerosols such as aluminum. Aluminium is a proinflammatory compound, and environmental exposure to the metal has been linked, albeit controversially, with neurodegenerative diseases such as Alzheimer's disease, Parkinson's disease and amyotrophic lateral sclerosis. ${ }^{10-12}$ Suspended aerosolised aluminium has the potential to prove a hazardous environmental exposure, warranting careful and close investigation as well as a precautionary approach before widespread deployment.

Sulfur aerosols to reflect sunlight are another candidate technology as part of the suite of geo-engineering proposals. Sulfur seeding of the stratosphere holds possibilities for ecological disturbance with human health implications. Sulfur aerosols mimic the global dimming effect that classically follows large-scale volcanic eruptions. However, studies suggest that these aerosols have the potential to deplete stratospheric ozone by serving as surfaces for heterogeneous chemistry. ${ }^{13}$ This could cause increased levels of carcinogenic solar ultraviolet-B energy to reach the surface with a potential impact on health and biological populations. Additionally, sulfur aerosols stand to perturb the sulfur and global hydrological cycles, contributing to the global acid rain burden with its concomitant health and ecological effects. 
Iron fertilisation of the ocean has also been undergoing experimentation and is mooted as a geo-engineering venture of choice. Iron is a limiting factor to phytoplankton growth in many parts of the ocean. Phytoplankton communities represent natural carbon capture and removal machinery. Apart from the dire scenario of unforeseeable interference with the pelagic food chain, iron fertilisation of the ocean could have more immediate and direct impacts on human health. Recent studies have shown, for example, that iron enrichment can favour the survival success of Pseudo-nitzschia species of algae. ${ }^{14}$ Pseudo-nitzschia commonly occur along coastlines and are responsible for the periodic closure of shellfish and finfish harvests due to the accumulation of neurotoxic domoic acid in the tissues of commercially and recreationally important marine species. ${ }^{14}$ More broadly, iron enrichment can enhance algal blooms with their well established health effects, including respiratory irritation and cyanobacterial illness. ${ }^{14}$

Geo-engineering may have indirect effects on human health as well. As a dual-use technology with militarisation potential, and with some countries already declaring strategic interest in weaponising weather, ${ }^{15}$ geoengineering has the potential for transboundary conflicts with devastating human impact. Moreover, geoengineering would need to be underwritten by a stable and long-lived international political accord for maintenance of these schemes. This heightens the risk of catastrophic climate change should some political disruption to geoengineering efforts occur.

International governance regimes over geo-engineering remain highly underdeveloped. The United Kingdom House of Commons Select Committee on Science and Technology has endorsed aspirational principles on governance - the so-called Oxford Principles. ${ }^{16} \mathrm{Geo}-$ engineering also arguably falls within the purview of existing international climate change accords such as the United Nations Framework Convention on Climate Change (1992) and the Convention on the Prevention of Marine Pollution by Dumping of Wastes and Other Matter (1972). International instrumentalities, such as the International Maritime Organisation, have also incidentally engaged with the subject. ${ }^{17}$ However, no instrument systemically makes explicit provision for the application of precaution with these technologies, let alone as they relate to human health.

Understanding the links between health and geoengineering is an urgent imperative as we chart a course in understanding how to mitigate, adapt to and possibly manipulate climate change. Human health stands to be

potentially affected directly and indirectly through geoengineering initiatives as they are presently conceived. The health ramifications of geo-engineering are speculative at present. Given the track record of unintended consequences from environmental manipulation, it is difficult to be unreservedly sanguine about geoengineering. The precautionary principle should prevail; and understanding potential effects on human health is urgent and necessary, given the increased favourability of geo-engineering techniques. By sounding a note of caution regarding geo-engineering's effects on health, the health community can act to give additional credence to calls for climate change mitigation through deep emissions cuts.

While these technologies may smack of science fiction, we are clearly living in the Anthropocene age
1 United Nations. Report of the United Nations Conference on Sustainable Development: Rio de Janeiro, Brazil 20-22 June 2012. New York: UN, 2012. http://www.uncsd2012.org/content/documents/

814UNCSD\%20REPORT\%20final\%20revs.pdf (accessed Aug 2013).

2 Horton R. The climate dividend. Lancet 2009; 374: 1869-1870.

3 McMichael AJ, Butler CD. Climate change and human health: recognising the really inconvenient truth. Med J Aust 2009; 191: 595-596.

4 Ganten D, Haines A, Souhami R. Health co-benefits of policies to tackle climate change. Lancet 2010; 376: 1802-1804.

5 Ayres JG, Forsberg B, Annesi-Maesano I, et al. Climate change and respiratory disease: European Respiratory Society position statement. Eur Respir J 2009; 34: 295-302

6 Silverman DT, Samanic CM, Lubin JH, et al. The Diesel Exhaust in Miners study: a nested case-control study of lung cancer and diesel exhaust. J Natl Cancer Inst 2012; 104: 855-868.

7 Victor DG, Morgan MG, Apt J, et al. The geoengineering option: a last resort against global warming? Foreign Aff 2009; 88: 64-76.

8 Schneider SH. Geoengineering: could we or should we make it work? Philos Trans A Math Phys Eng Sci 2008; 366: 3843-3862.

9 Steffen W, Persson A, Deutsch L, et al. The anthropocene: from global change to planetary stewardship. Ambio 2011; 40: 739-761.

10 Win-Shwe TT, Fujimaki H. Nanoparticles and neurotoxicity. Int J Mol Sci 2011; 12: 6267-6280.

11 Tomlienovic L. Aluminium and Alzheimier's disease: after a century is there a plausible link? J Alzheimers Dis 2012; 32: 517-518.

12 Blaylock RL. Aluminium-induced immunoexcitotoxicity in neurodevelopmental and neurodegenerative disorders. Curr Inorg Chem 2012; 2: 46-53.

13 Rasch PI. An overview of geoengineering of climate using stratospheric sulphate. Philos Trans A Math Phys Eng Sci 2008; 366: 4007-4037.

14 Moore SK, Trainer VL, Mantua NJ, et al. Impacts of climate variability and future climate change on harmful algal blooms and human health. Environ Health 2008; 7 Suppl 2: S4.

15 House TJ, Near JB, Shields WB, et al. Weather as a force multiplier: owning the weather in 2025. (US Air Force research paper presented to Air Force 2025.) 1996. http://www.fas.org/spp/military/docops/usaf/2025/v3c15/v3c15-1.htm (accessed Aug 2013).

16 Rayner S, Heyward C, Kruger T, et al. The Oxford Principles. Climate Geoengineering Governance Working Paper 1. 2013. http://www. geoengineering-governance-research.org/cgg-working-papers.php (accessed Aug 2013).

17 International Maritime Organisation. Parties to international dumping treaties express concern regarding reported iron fertilization incident. 34th consultative meeting of contracting parties to the Convention on the Prevention of Marine Pollution by Dumping of Wastes and Other Matter, 1972 (London Convention) and 7th meeting of contracting parties to 1996 Protocol thereto (London Protocol). Briefing: 47: November 2, 2012. http://www.imo.org/MediaCentre/ PressBriefings/Pages/47-ocean-fertilisation.aspx (accessed Aug 2013). 